\title{
I "see" what you are saying: The analytical work of diagrams in online discussions
}

Tony Stevens

University of Melbourne

\begin{abstract}
Diagrams illustrating research on discussion forum content in online education practices can assist to clarify an author's thoughts and assist with the reader's comprehension. A review of past practices in the use of diagrams to explain, demonstrate or propose research findings shows a diversity of practices emerging from naturalistic settings. The tracing of online discussions is sometimes practiced by mapping the activity of participants using peer interaction patterns through a social network analysis or by imposing a problem-solving framework as a heuristic. Other approaches include diagrams that illustrate learning outcomes from discussions rendered by parsing data against pre-defined categories such as Bloom's taxonomy. Though the approaches described in the literature here have an innovative or novel character, there is limited evidence of wider-scale uptake in the broader literature relating to analysis of online discussions. Likewise, the practice of graphic elicitation to assist in developing research findings in this area is lacking and an area for future development.
\end{abstract}

\section{Introduction}

Studies of educational practices involving online discussions have attracted attention from researchers over the past decade as they have sought to explore the value provided by this technology for both distance and blended-learning settings (Hsu, Chou, \& Chang, 2011; Liu \& Tsai, 2008; Suthers, Dwyer, Medina, \& Vatrapu, 2010). Since transactions in a discussion involving large undergraduate cohorts can span many weeks and consist of hundreds of postings on an individual topic (Dringus \& Ellis, 2005), analysing educational outcomes in this environment poses many challenges. Attempts have been made to develop classification systems to evaluate the content in online discussions (Chan, Hew, \& Cheung, 2009; Hara, Bonk, \& Angeli, 2000). Learning styles suggested from the analysis of text practices (online discussions) have also been proposed (Knowlton, 2005). Other areas of analytical concern about online discussions include: (a) the health of discussions (Dringus \& Ellis, 2010), (b) interaction between learners (Stevens, 2013), (c) the development of critical thinking skills (Richardson \& Ice, 2010), and (d) knowledge-building (Schrire, 2006).

A heuristic device sometimes used to represent learning encounters in education is the diagram (Barab, Hay, \& Yamagata-Lynch, 2001; de Freitas, 2012). The work that diagrams might do for us in online discussions is important, since we are dealing with a "fast-moving object of analysis" (Beneito-Montagut, 2011; p. 720) in online learning spaces. Can images provide useful amplification of the learning dynamics such as those emerging in online asynchronous discussions? This paper provides a review of the diagrams used in analytical work relating to online discussions. The purpose of this paper is to explore what diagrams do in the analytical practice of educational settings that involve online discussions.

Locke and Daly (2006) suggest that "we inhabit a text-saturated world, in which we negotiate via a repertoire of textual practices” (p. 39). Despite this hegemony of text, in published works, visual representation serves to clarify an author's thinking and helps the reader's comprehension (Whetten, 1989). There is however, the concern of the "pictorial assumption" (Ittleson, 1996; p. 176): that a diagram represents reality or that reality can be reflected in a diagram. As Ittelson (1996) notes, this assumption is rarely challenged in analytical work involving images and pictures.

The employment of images in communicating information can, in part, be understood using Blackwell and Engelhardt's (2002) taxonomy. The multi-dimensional framework that they identify through their review of the literature includes: (a) the discourse resulting from the interaction of the user's cognition and the embedded social context; (b) the task interaction and the diagram itself; and (c) the mode of correspondence between the diagram and the represented information. Another useful category they propose concerns the characterisations used to represent a concept. These include: (a) a basic vocabulary - properties of each element: line, circle, arrow, colours; (b) conventional elements - word, shape, and/or picture; (c) pictorial 
abstraction - in resolutions ranging from a symbol to a photograph; (d) the graphic structure - a network, set of segments, and/or axes; (e) a mode of correspondence (either structurally or correspondence with represented elements, i.e. resolution) - literal, metaphoric, or arbitrary; and (f) the represented information.

Together the two elements above (context and represented information) constitute a form of diagrammatic literacy that informs the discussion below. The challenges faced by researchers and educators in providing visual displays of the results of conversations are analogous to that of the cartographer and the chronicler, since asynchronous discussions occupy time, distance and rhetorical space (Locke, 2007). The expectation is that such images can be used to explore asynchronous conversations that include both transactional and physical distance (Bender, 2003).

For the present review, a total of 60 papers relating to asynchronous discussions on learning management systems (LMS) were drawn from several databases (EBSCO, Science Direct and ProQuest). From those papers, 12 were identified that had a diagrammatic component and were selected for further review (see Appendix A). The contribution that diagrams made in those 12 papers was considered in the context of the area being investigated by the author(s). The use of nomograms to depict causal relationships between variables of interest (e.g., LaPointe \& Gunawardena, 2004) is not addressed in this paper as these diagrams represent a conventional translation of quantitative variables showing direction and strength, rather than text-diagram synthesis, the core concern of this paper.

The diagrams in the research presented below could best be summarised as providing two key functions. They illustrate teaching practice that enables users of LMS (both teachers and students) to: (a) understand the meaning of content generated in the learning space; and (b) to show research findings to readers in some aspect of teaching practice that may illuminate the learning process. The type of problems presented to researchers in these scenarios involves: (a) making sense of large and dynamic pools of data where there are concerns about interaction; (b) understanding the dynamics of unfolding transactions as they relate to the teaching and learning process; and (c) illustrating "knowing in the making” (Barab et al., 2001; p. 64) that enables further and deeper insights into teaching and learning practice.

The diagrammatic practices described below demonstrate that a range of graphic approaches are being employed that have common features, but have been derived for diverse purposes, for example to track cognitive activity, to understand unfolding learner-learner dynamics in discussions, or track events as learning tasks are undertaken. It is noteworthy that as a practice, only one method described below has a long-standing empirically-derived claim for its employment to illustrate social interactions (social network analysis). In addition, only one of the diagramming methods described claims the rigour of being able to represent human-technology interactions faithfully (contingency graphs).

\section{Event tracking relating to teaching and learning}

Oliveira, Tinoca, and Pereira's (2011) study involved tracking two groups of master's level students in a group assignment conducted using a discussion forum to facilitate their interactions. The authors analysed the interactions of the participants and developed a four-level classification of the activities of the groups which included, (a) negotiation, (b) research, (c) conception, and (d) production. Designed as a study of collaboration in small groups with a learning task, the study highlighted contrasting performances between the groups in the final product (a term paper). The group that was said to have been more effective exhibited more supportive posting behaviour, more responses to individuals' posts and greater sharing of information. Oliveira et al.'s (2011) diagram representing "temporal dispersion and duration of both groups' patterns of work" (p. 1354) serves to illustrate the contrasting functioning of the groups. The graphic structure is a hybrid, based on an axis (time), segmented components (activity) and words. The diagram takes the role of illustrating the study (see Figure 1 below). 


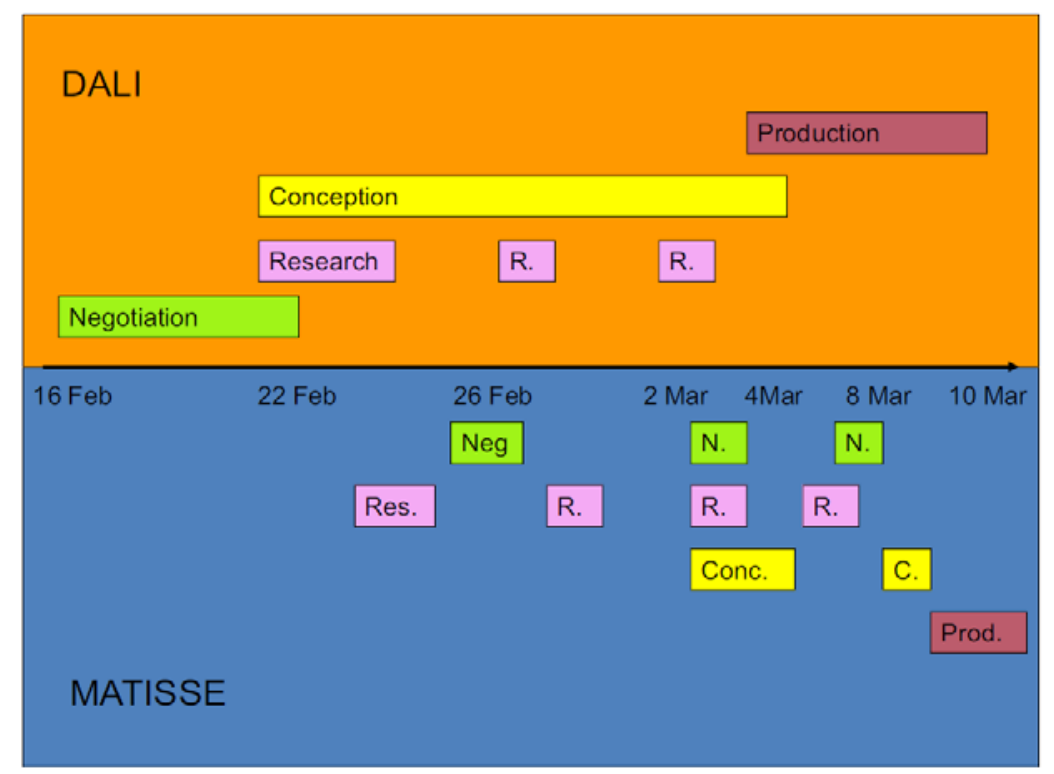

Figure 1. Group activities in an assignment (Olivera, 2011)

The researchers reported that the group designated Dali performed better in the analysis of the final assignment product. There are several properties of each group's performance that are highlighted by the diagram, including: (a) a later start of the negotiation phase for Matisse; (b) an earlier and longer negotiation phase for Dali; and (c) a more disruptive pattern of activities for Matisse. The diagram does the work of illustrating timing and duration in each of the author's categories of activity.

Earlier work by Liu and Tsai (2008) on problem-solving in student groups took an alternative perspective. In their study, the authors employed a problem solving model - the issue-based information system (IBIS) to examine the types of interactions that students in a computer programming course might develop as they set about solving a problem within a limited time-allocation. The IBIS model suggests that student discussions might take the form of: "proposing issues, offering positions, making arguments and responses, and then showing supports or objections" (Liu \& Tsai, 2008; p. 630). Using a set structure for each small problem-solving group, the authors displayed the interactions of the participants using conventional diagram elements, adding text symbols representing programming abilities (low - L, medium - $M$ and high - H).

A section of the interaction diagram is shown at Figure 2 for 6 of the 14 groups studied. The direction of communication and the number of positions offered is shown in the group diagrams. In this case, circles represent students and lines with arrows represent direction and position(s) offered. Considering the development of the groups and the nature of their exchanges (content analysis), the authors concluded that various categories of interaction emerged, including (Liu \& Tsai, 2008): (a) centralised knowledge exchange (single expert responder) - see Group A; (b) distributive knowledge exchange (shared exchange) - see Group B; (c) impediments based on either limited individual (programming) ability - see Group E, or weak group development - see Groups C \& D; and (d) partial knowledge exchange (selected instances of collaboration between group members) - not shown below. 

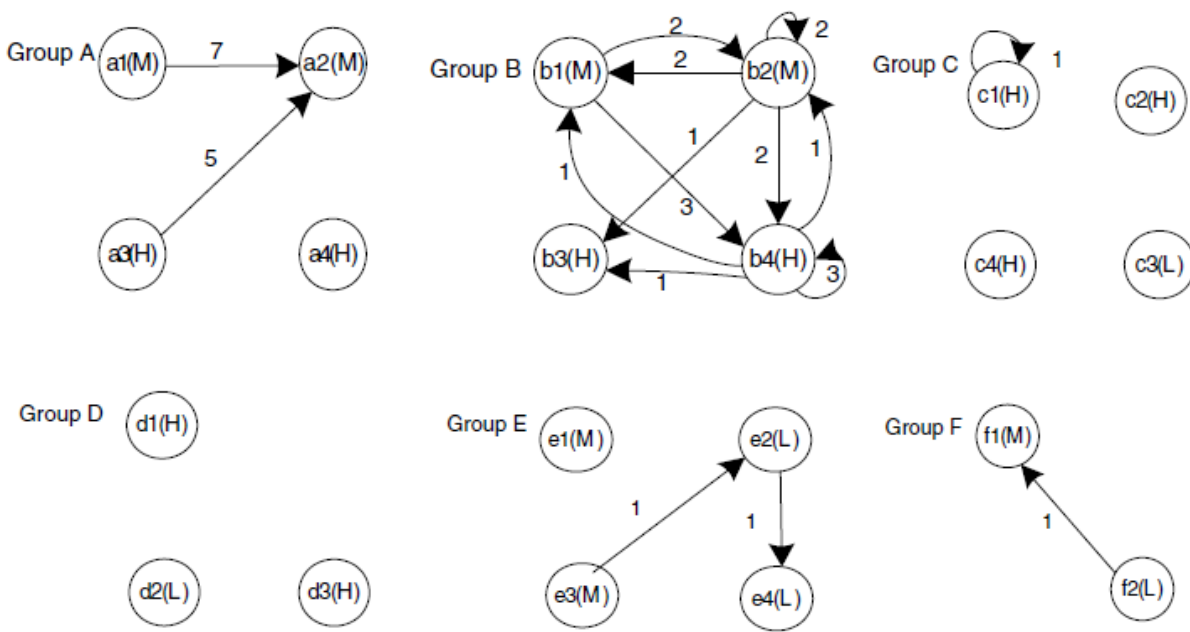

Figure 2. Peer interaction in small group problem-solving (Liu \& Tsai, 2008)

\section{Learning in-the-making (i): Looking at practices}

The cognitive aspects of online knowledge sharing and the structural development of online conversations was a concern of Hara et al.'s, (2000) study of a graduate level educational psychology course being taught in a blended-learning mode. They were concerned to show how structures of conversations developed through a starter-wrapper technique applied to the course readings (One student reads and asks questions about the readings on a discussion forum before a lecture [starter]; the others comment/answer and one student [wrapper] summarises the discussion on the readings for the week). Conversations on the various forums were mapped showing the development of interactions between students. Following an early model of mapping online conversations (Howell-Richardson \& Mellar, 1996), the diagrams in the paper were used to illustrate findings about the contrasts in interaction between early starter-centred conversations and later synergistic ones. The differences are apparent by examining the structure of the discussions shown in Figures 3 and 4 below.

Using Henri's (1992) content-analysis model, Hara et al. (2000) developed the conversation maps to demonstrate the impact of differing levels of interaction including: social, interactive, metacognitive and cognitive, noting that this transition was "not always as linear as Henri's (1992) model might suggest" (Hara et al., p. 123). In Figure 3, early in the course, the interaction pattern appears to be centred on the starter (designated " 1 " in the box). Two of the students make no contribution at all (isolated circles 21 and 22), while several others remain connected only at the periphery. In Figure 4, later in the course, it is apparent that the network of interactions is more dense, less centralised and there are no isolated group members. 

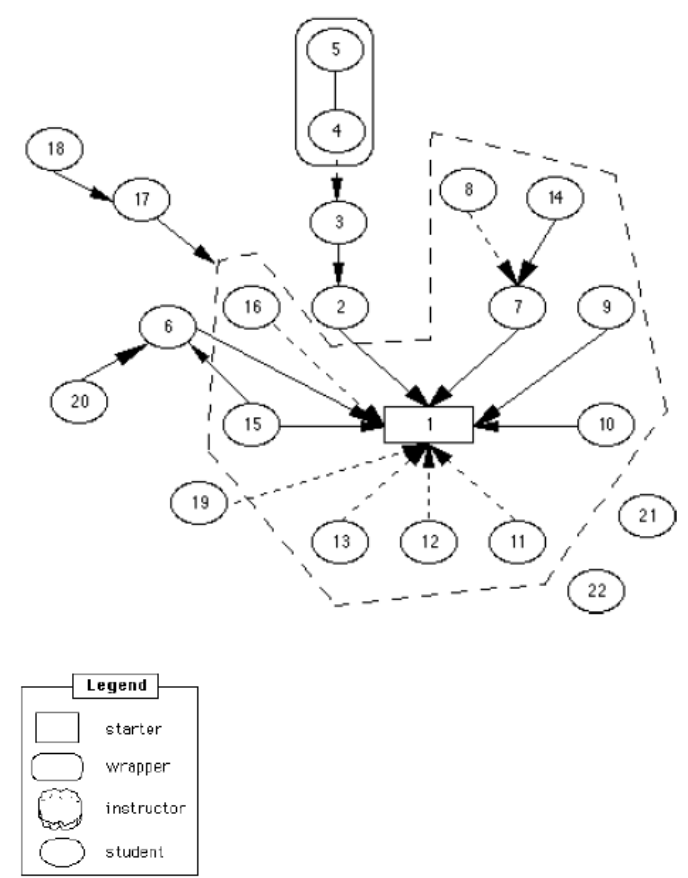

Figure 3. A starter-centred discussion from Week 2 (Hara et al., 2000)
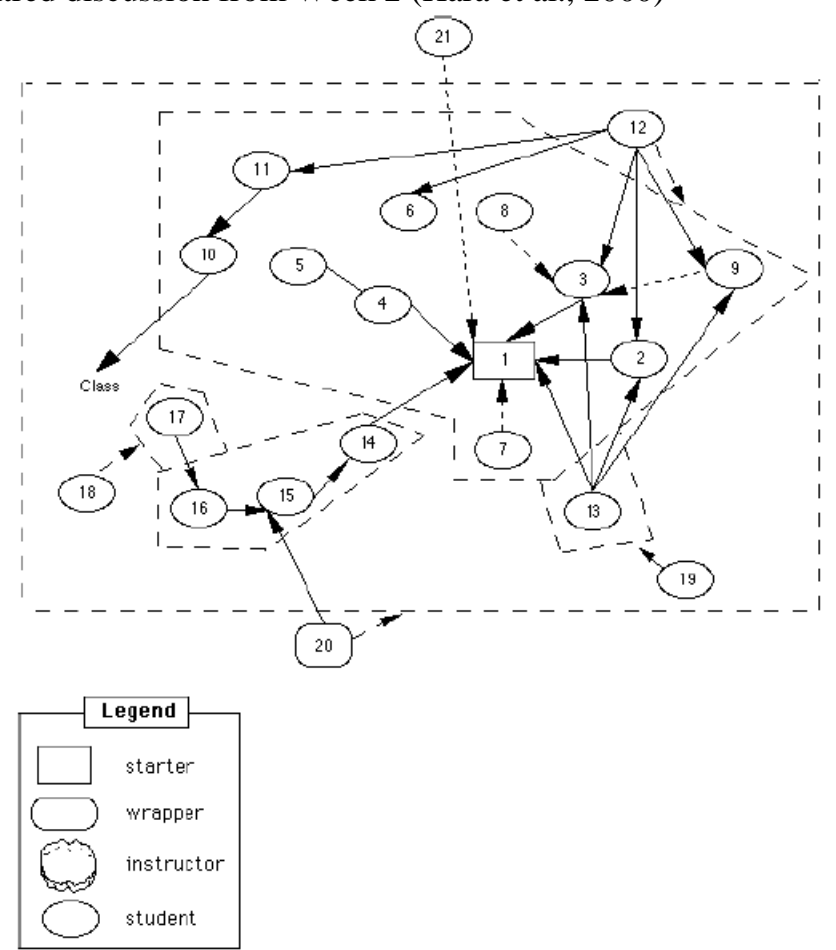

Figure 4. A synergistic discussion from Week 8 (Hara et al., 2000)

The diagrams here are doing the work of hybridising the findings of the researchers, since they are charged with showing: (a) the researcher's perception of individual message contributions to the whole conversation, (b) who interacted with whom over time, and (c) the relative position in the conversation of each participant (and their formal or designated role). This hybridising work suggests that diagrams can help one to think with concepts and bring them together to communicate in a way that is an alternative to words alone. 


\section{Another conversation map}

Citing both Hara et al.’s (2000) and Howell-Richardson \& Mellar's (1996) work, Schrire’s (2006) study involved an examination of interactions in an asynchronous discussion between students and their teachers based on content analysis with a group of students undertaking doctoral-level studies. The researcher set out to examine patterns of interaction, discourse and distributed cognition in the knowledge-building process being undertaken in the discussions. She took a view that discussions and the threads within them constituted a sequence of exchanges, and an individual message a "conversational turn” (p. 54). Sampling purposefully, the author selected a group of conversations from across the cohort of students that were designed to "maximise and minimise similarities and differences" (p. 56). For this study, forums were differentiated as either instructor-moderated or student-only. Schrire reviewed the length and content of each posting in relation to word count and correspondence with Bloom's (1956) and Biggs and Collis's (1982) SOLO Taxonomies, and the Practical Inquiry Model of Cognitive Presence (Garrison, Anderson, \& Archer, 1999). Interaction was reviewed using a mapping technique for the forums of interest (see Figure 5 below for two selected conversation threads) and a graphical technique (bar chart) for comparing the cognitive activity. In these figures, the instructor is designated with the heavy-lined circle.

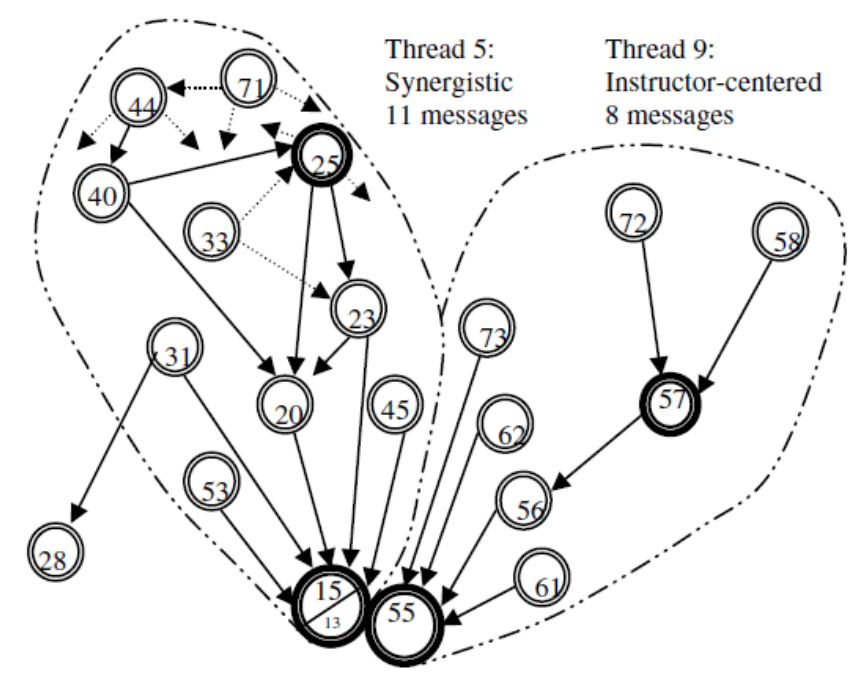

Figure 5. A comparison of instructor-centred and synergistic discussions - Schrire (2006)

The messages in specific discussions underwent discourse analysis to establish moves described as having a function of either: demanding, giving or acknowledging. This so-called "micro level of discourse analysis" (Schrire, 2006; p .60) enabled the production of a macro-level interaction map, shown above in Figure 5. Of particular interest in this diagram is the distinction between a synergistic discussion and an instructor-led one. A synergistic conversation (Thread 5) shows more connections between the students and other students and instructors, while an instructor-led discussion as displayed in Thread 9 shows fewer connections among each of the actors and a convergence on the instructor. Although the diagram was published as a "partial view of the interaction patterns found" (Schrire, 2006; p. 61), some trends can be observed: (a) synergistic discussions involve interaction between more participants; and (b) instructorcentred discussions tend to have a more singular focal point (i.e. the instructor). The detailed diagrams developed in the 2006 study are referenced back for the reader to examine in her earlier 2004 study (Schrire, 2004). A diagram from this study is included below at Figure 6 that shows a larger number of discussions and illustrates the "cluster of messages interacting with one another around sub-topics of the conference" (p. 483).

Because not all threads of conversation are re-presented as nodes in the diagram, the researcher has become the "creator of a re-creation" (Svensson, 2009; p. 181), that serves to illustrate several patterns of discussion: (a) instructor-centred; (b) synergistic; (c) developing synergism; (d) scattered; and (d) student-centred. 


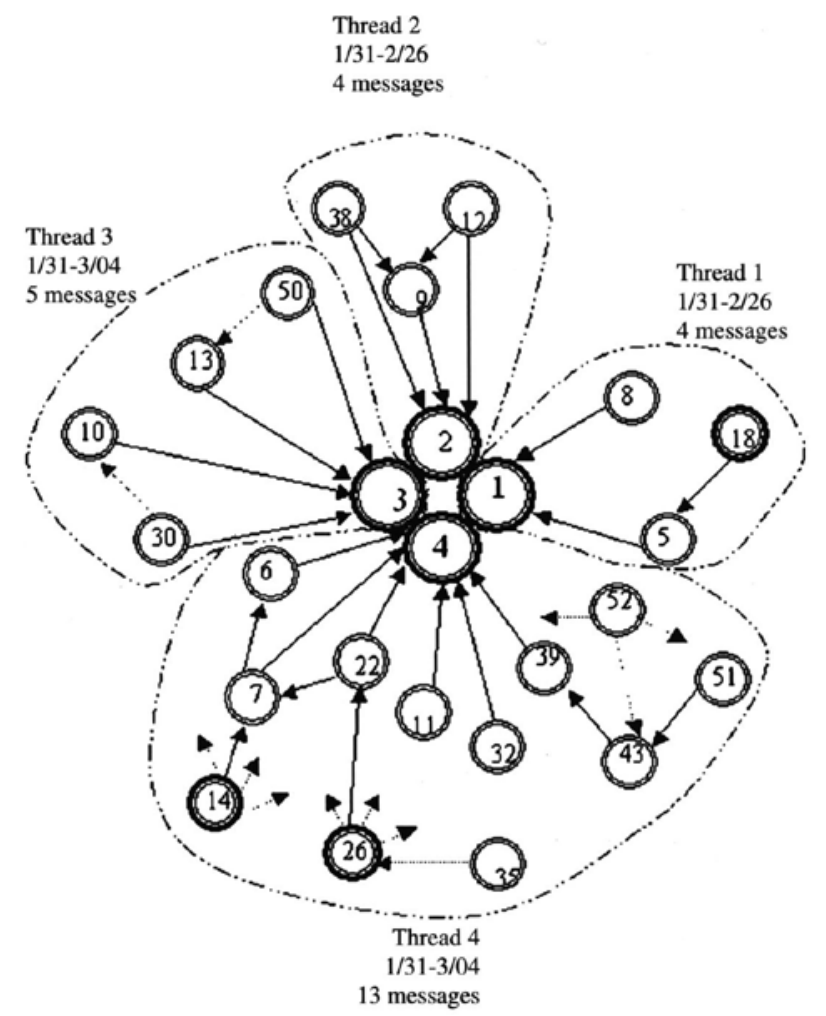

Figure 6. Patterns in a forum showing differing interaction types (Schrire, 2004)

\section{Learning in-the-making (ii): A micro-analytic look at practices}

Developing concurrently, some scholars have also concerned themselves with examining the activities and interactions (i.e. practices) of students in discussions. This examination is claimed to offer analytical insights across “actors, media, space and time” (Suthers et al., 2010; p. 2). Their work stretches the divide between statistical analyses (designed to represent frequency and type of interaction in collaborative work) and an examination of the learner's working environment, activity (discussion forum posts, submitted work like essays and data log files) and peer-interaction(s). This empirically derived diagram - contingency graph - is sometimes displayed across a temporal axis and annotated to show direction of communication, media, and collaborators.

Contingency graphs attempt to "unify data derived from various media and interactional situations" (Suthers et al., 2010; p.3) for example the interaction between participants in online learning activities and their technology, the teachers, and other learners. The analytical schema of the contingency graph and a generic example are shown below in Figure 7. In the schema, uptake is said to be a distinguishable activity grounded in a manner in which "specific actions and the relationships between them" can be recognised (p. 7). A contingency provides a distinction between evidence and interpretation for analytic purposes. Examples of contingencies include (p. 14): "media dependency" (responding to a thread in a discussion), "semantic relatedness" (where two discussion threads might contain similar concepts - whether they are related is not assumed - it is considered a latent relation), or some form of "spatial organisation" (for example placing items near each other in a workspace). 

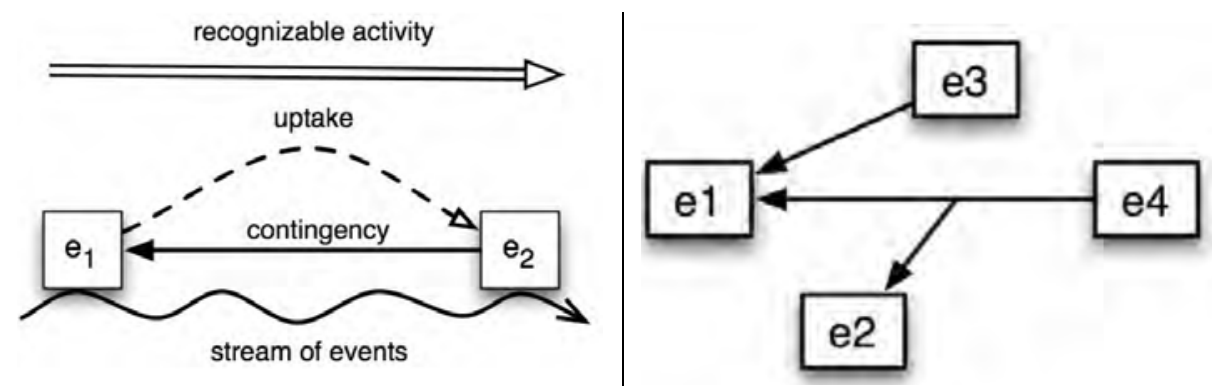

Figure 7. The analytic schema (left side) and a sample of a contingency graph (right side) (Suthers et al., 2010)

In articulating the contingency graph as an analytical construct, Suthers et al. (2010) go beyond the online discussion and capture a comprehensive view of the learning experiences of particular groups and individuals. The authors acknowledge that their method results in large and complex contingency maps a reflection they say of the richness of human interaction, rather than a "limitation of the contingency graph approach” (p. 29).

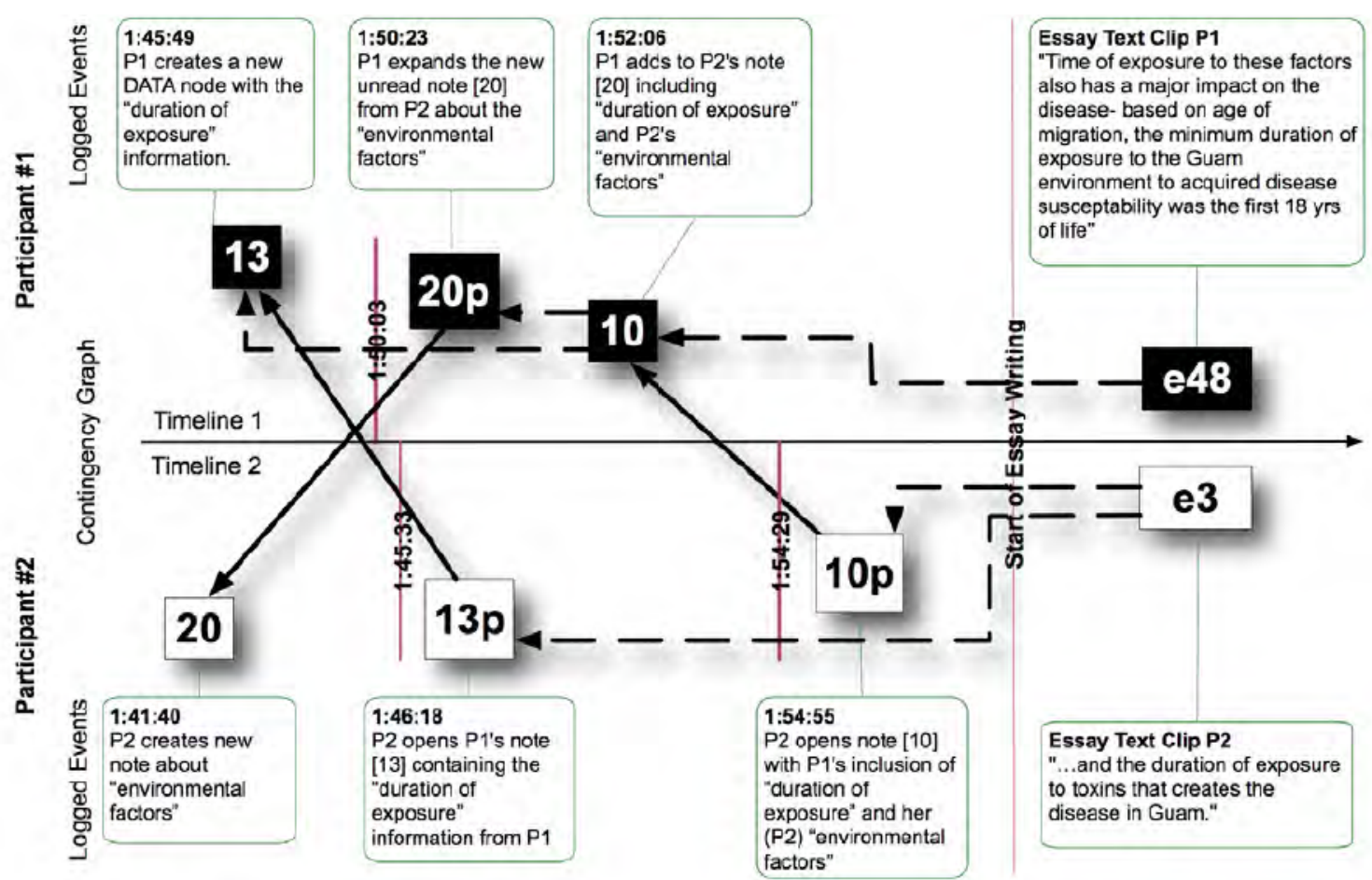

Figure 8. A fragment of a contingency graph (Suthers et al., 2010)

Figure 8 shows two individuals participating in an interaction online and using their individual graphical workspaces over time (to collaborate in building subject knowledge). Activities were tracked using video of their screens, comments or notes made on their workspaces and excerpts of text from their submitted work. Letters and numbers are used as shorthand for actions by students and the text boxes are explanations of what was done, not part of the contingency graph. What is seen here is a small slice of 180 events that took place in this encounter. This diagram is different to those described in the preceding sections because it is an attempt to faithfully illustrate the nature of the analytic device in the researcher's work. The authors, alluding to Latour's (1990) concept of non-human materials mediating practices, suggest that their work encompasses "analytic practices in studies framed by diverse and potentially incommensurate world views" (Suthers et al., 2010; p. 30). Further, they suggest that "advances in other scientific disciplines have been accompanied with representational innovations, and shared instruments and representations mediate the daily work of scientific discourse” (p. 30). This work is done in part by diagrams. 


\section{Observing learning interactions in-motion}

In contrast to the preceding studies, the next two papers represent a more operational level of analysis. Each is a tool that can be used by academic staff to observe or give feedback, and by students to assist with selfmonitoring. The diagrams that are used in these papers serve to illustrate the concept being described by the researcher, but also how the tool might be deployed to assist in the field. In that sense, the method of the researchers suggests an adapted form of graphic elicitation (Crilly, Blackwell, \& Clarkson, 2006) not present in the other papers in this review.

TrAVis is a monitoring tool that is designed to assist students to reflect on their learning based on data that indicates their level of social, cognitive and behavioural inputs to a learning management system (May, George, \& Prévôt, 2011). TrAVis is a dashboard style of interface that offers feedback on a series of indicators based around online discussion metrics - for example the number of messages initiated or replied to, and the types of activity undertaken that might indicate learning such as browsing, reading, chatting and so on. In this case, May et al. (2011) use diagrams to provide examples of the employment of their monitoring and feedback system. These take the form of radar charts (Kiviat diagrams), with activities of interest on a variety of axes. These are offered at the individual and group levels of activity (see Figures 9 and 10 below).

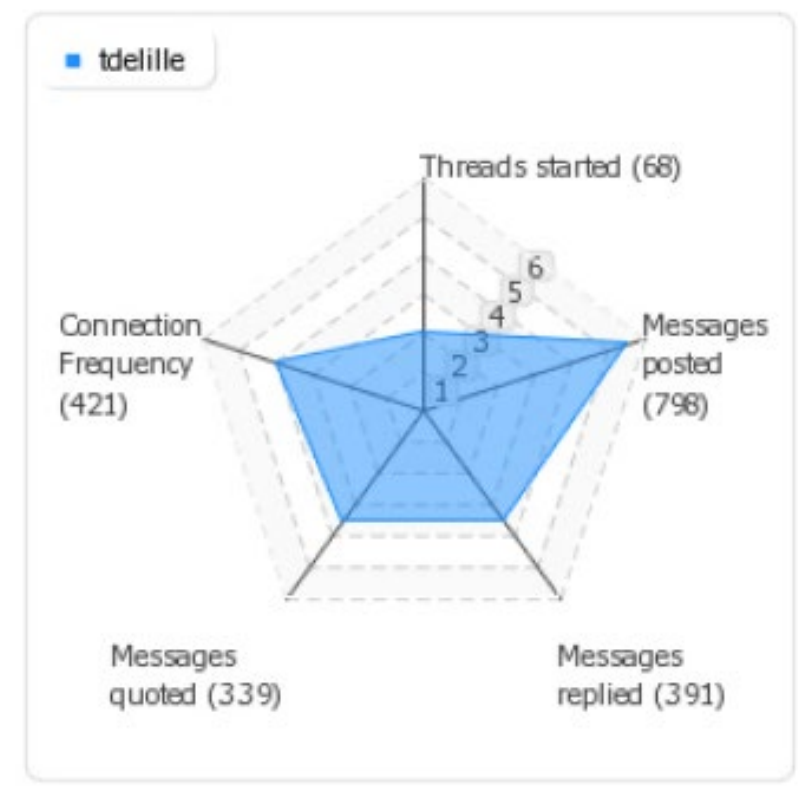

Figure 9. A selection of activity indicators (individual) in TrAVis (May et al., 2011) 


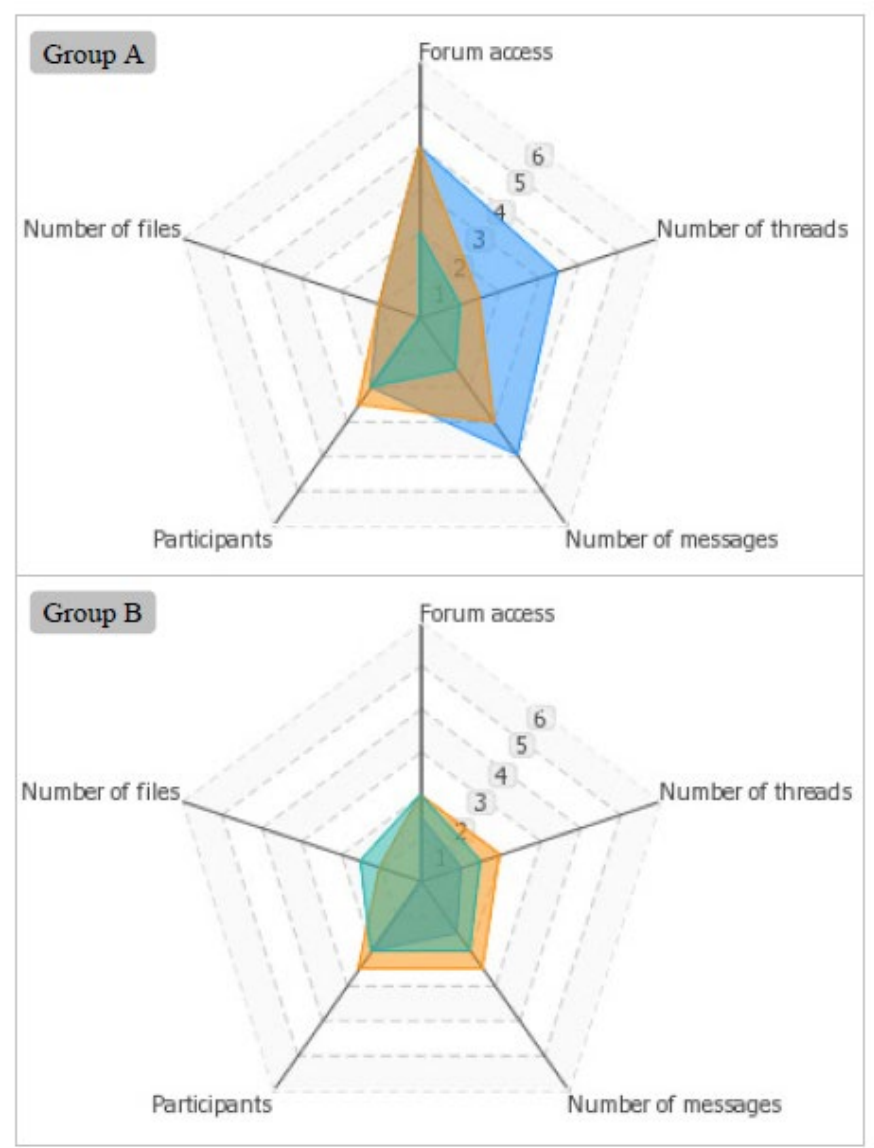

Figure 10. A selection of activity indicators (group) in TrAVis (May et al., 2011)

In this study, feedback on the field use of the tool was sought from students and teachers. It was reported that the diagrams helped to illustrate the data that users had accessed and provided evidence that the system had met the purpose for which it was designed (student self-reflection and monitoring of different levels of interaction amongst students by teachers).

\section{Parsing text data and giving feedback: EduMiner}

Another system developed to assist in providing feedback from discussions visually can be seen in research relating to students' posts on discussion through text-mining (Hsu et al., 2011). The researchers developed a set of algorithms related to Bloom's (1956) taxonomy and by parsing discussion data through text-mining software, they constructed a cognition circle showing each participant how their contribution varied from lower level (knowledge indicator) to higher level (evaluation indicator) outcomes.

In order to provide formative feedback on the students' work, the software developed a collective cognition circle which compared with the particular individual's outcome in the discussion. The cognition circle was generated via an application called EduMiner. The value of being able to see each individual's progress in a discussion and its potential to promote learning is made apparent in this study by including a diagram to illustrate an individual's cognition circle (see Figure 11 below). In this particular example, the analysis of the individual's contribution to the discussion, the inference could be drawn that their text showed evidence of higher levels of application and synthesis than say, analysis and evaluation. 


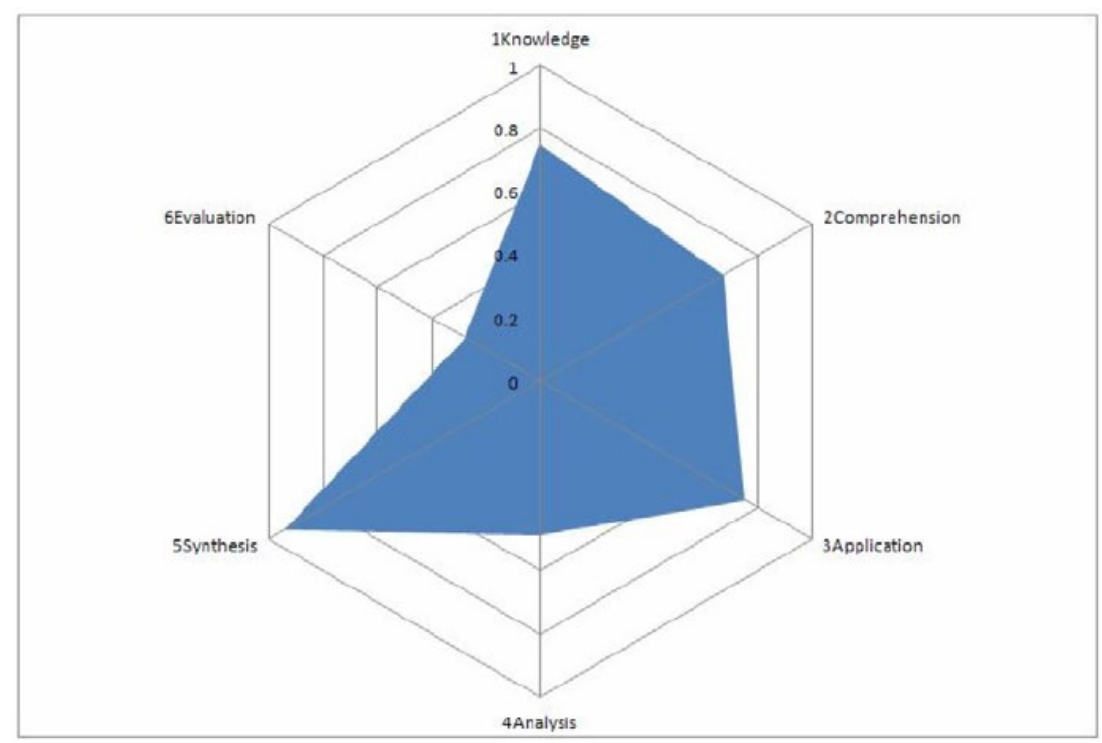

Figure 11. A sample of an individual’s cognition circle (Hsu et al., 2011)

\section{Large and dynamic pools of data: Social interaction and learning}

One discipline having an increasing influence in the field of understanding student interaction with technology is that of social network analysis (SNA). Structural analysis has a long tradition dating back to early observations of social interaction of various kinds - including the observation of school children during play time (Bott, 1928; Wellman, 1926) - and has progressed from the early sketches of Jacob Moreno (1953), to a new branch of social science that has been harnessed to understand small world concepts. SNA provides an opportunity to view the use of discussion forum technology as an exchange of messages. The method provides the researcher with a top down view of the communication network showing participants as nodes in a network. Unlike the other conversation maps described above, SNA diagrams are developed using algorithms that evolved from Moreno's socio-gram concept, enabling relationships in the structure to be mapped quantitatively by using graph theory (Freeman, 2004). SNA has been adopted in other disciplines, such as organisational studies (Cross \& Parker, 2004), and diffusion networks (Rogers, 2003).

At the network level, Macfadyen and Dawson (2010) reviewed the discussion forum transactions of 118 students undertaking courses of study in biology at the University of British Columbia. The purpose of the study was to develop a case for using SNA as a diagnostic tool to identify students at risk of failure or dropout. The diagrams generated provided the authors with a ready-made diagnostic tool that could highlight individuals who might be left out of important learning interactions, or others whose social position could be beneficial to their peers in the network.

In this particular case the size of nodes in Figure 12 indicates the relative number of connections of the student represented by a circle. Further, by considering the students' connections through the SNA diagram, students who were absent or peripheral to the discussions are shown. Further to the nodes presented in Figure 12, the colours of the nodes in Figure 13 correspond with the academic results of the students positioned in a chosen network with (a) red - A, (b) orange - B, (c) yellow - C, and (d) blue/black - D or fail. The diagnostic value it is claimed is derived from the function of the online technology deployed social network adapting pedagogical practice (SNAPP) (Dawson, Bakharia, Lockyer, \& Heathcote, 2011) and the analytical skills of the teacher to identify those who might be struggling and intervene and either re-direct the student into a mentoring relationship, or to take direct action in the teaching and learning process. The diagrams that emerged in the study reflected the structure of the networks that could be seen in real time by those undertaking the research. 


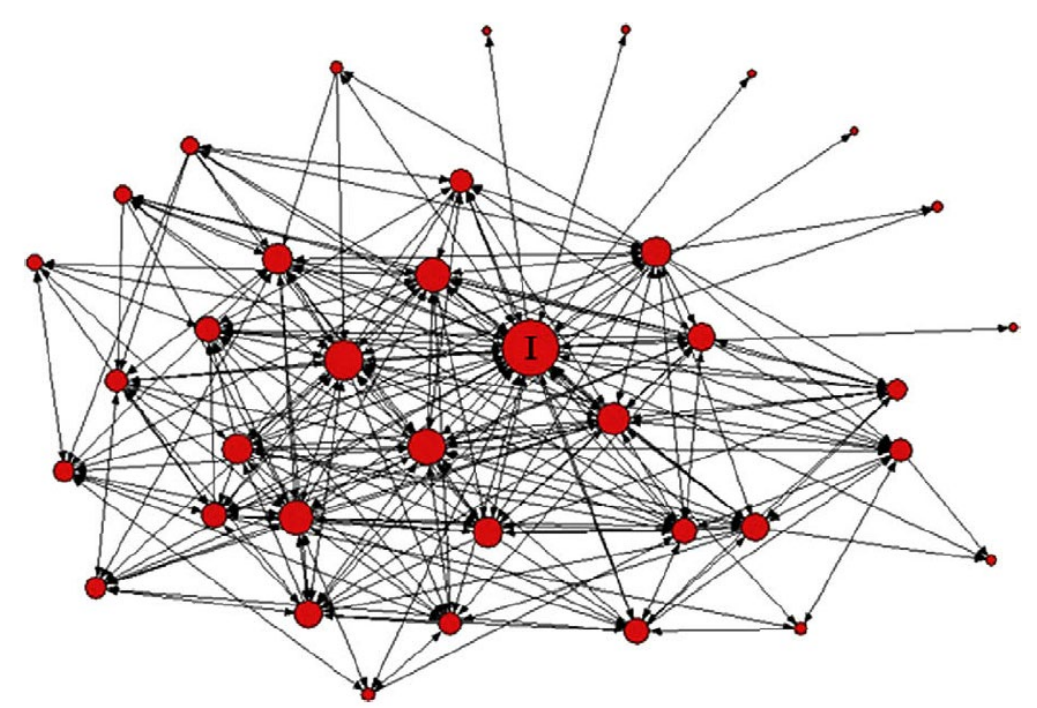

Figure 12. Social network analysis of student conversations peer-peer and with an instructor (Macfadyen \& Dawson, 2010)

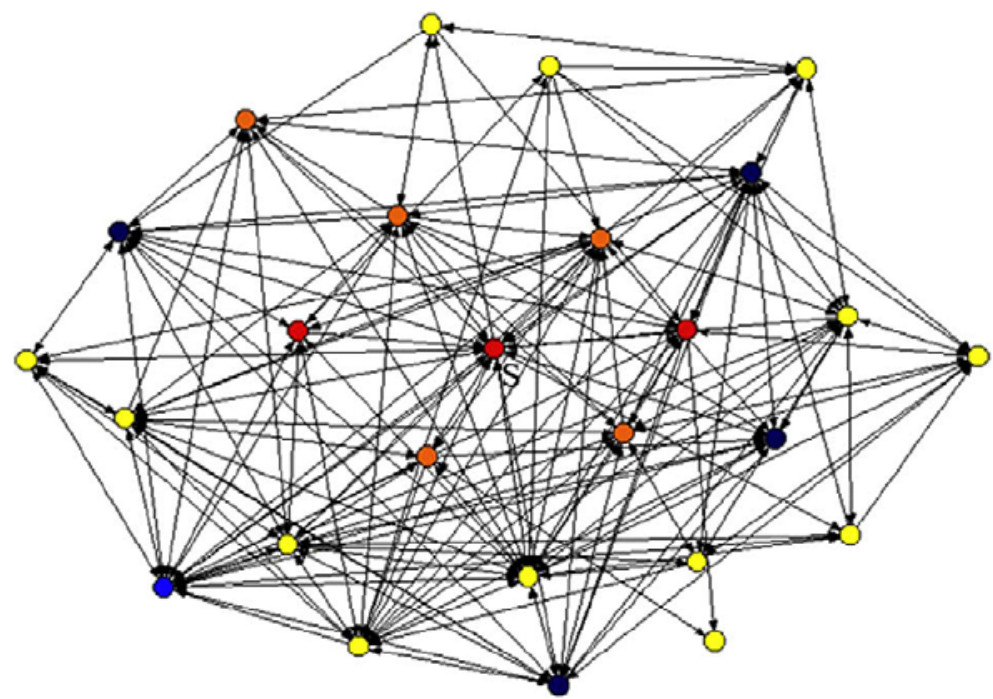

Figure 13. Social network analysis of student conversations centred on a particular student "S" (Macfadyen \& Dawson, 2010)

Similar techniques were applied by Dawson (2010) to identify the different types of networks developed during online discussions and the networks of higher and lower performing students. SNA was also employed by Stevens (2013) to illustrate the patterns of interaction among students whose posts had higher response rates in a blended learning environment.

\section{People garden: Beauty and function?}

The final example of the employment of diagrams to assist in understanding discussions is drawn from the wider literature relating to online discussions in general: People Garden (Xiong \& Donath, 1999). Addressing similar questions to those in the studies raised above but paying particular attention to the aesthetic value of the diagram, the authors of this study developed a visually striking diagram that uses a garden metaphor to identify individuals and their data profiles. Participants are visualised as flowers, with their messages represented by petals and responses to their post(s) by a pistil-like graphic. The passage of time in their participation is represented by the length of the stem. The age of posts is also denoted by the colour of the petals. The elements and sequence of how a people flower might develop is shown below in Figure 14. 


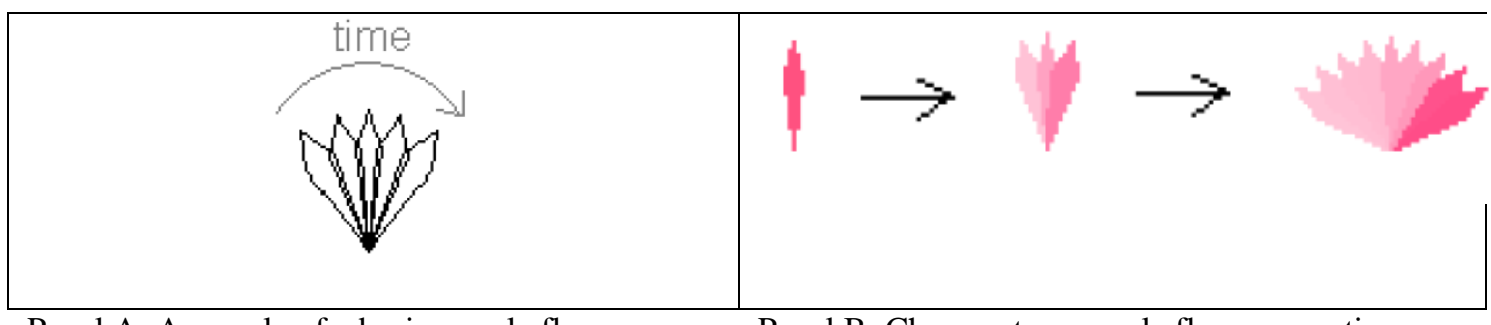

Panel A: A sample of a basic people flower

Panel B: Changes to a people flower over time

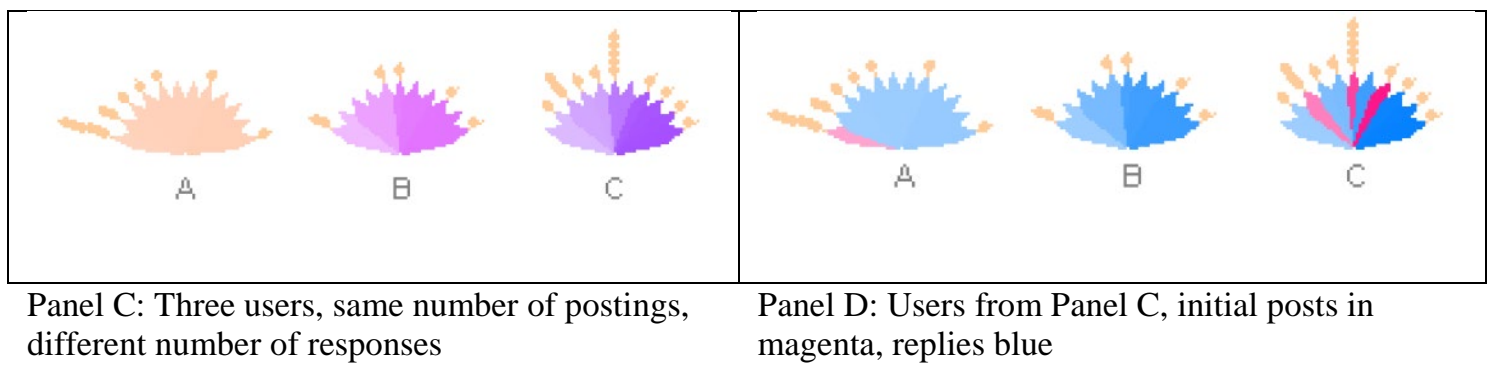

Figure 14. Panels A-D: Development of the flowers for People Garden (Xiong \& Donath, 1999)

Of those diagrams reviewed for this study, People Garden perhaps is the one that most speaks for itself. If participation is considered an indicator of discussion health, reviewing Figures 13 and 14 below helps to illustrate this in two contrasting discussions. The eye is drawn to the developing scenario presented on the left side of Figure 15. Here, there are many conversations that have developed over time, with many correspondents. We might consider this garden prolific. The effect being demonstrated through the illustration on the right side is that of a single dominant voice, shown as a tall, mature bloom. The discussion (garden) on the right is sparsely populated and contrasts sharply with the garden (discussion) on the left.

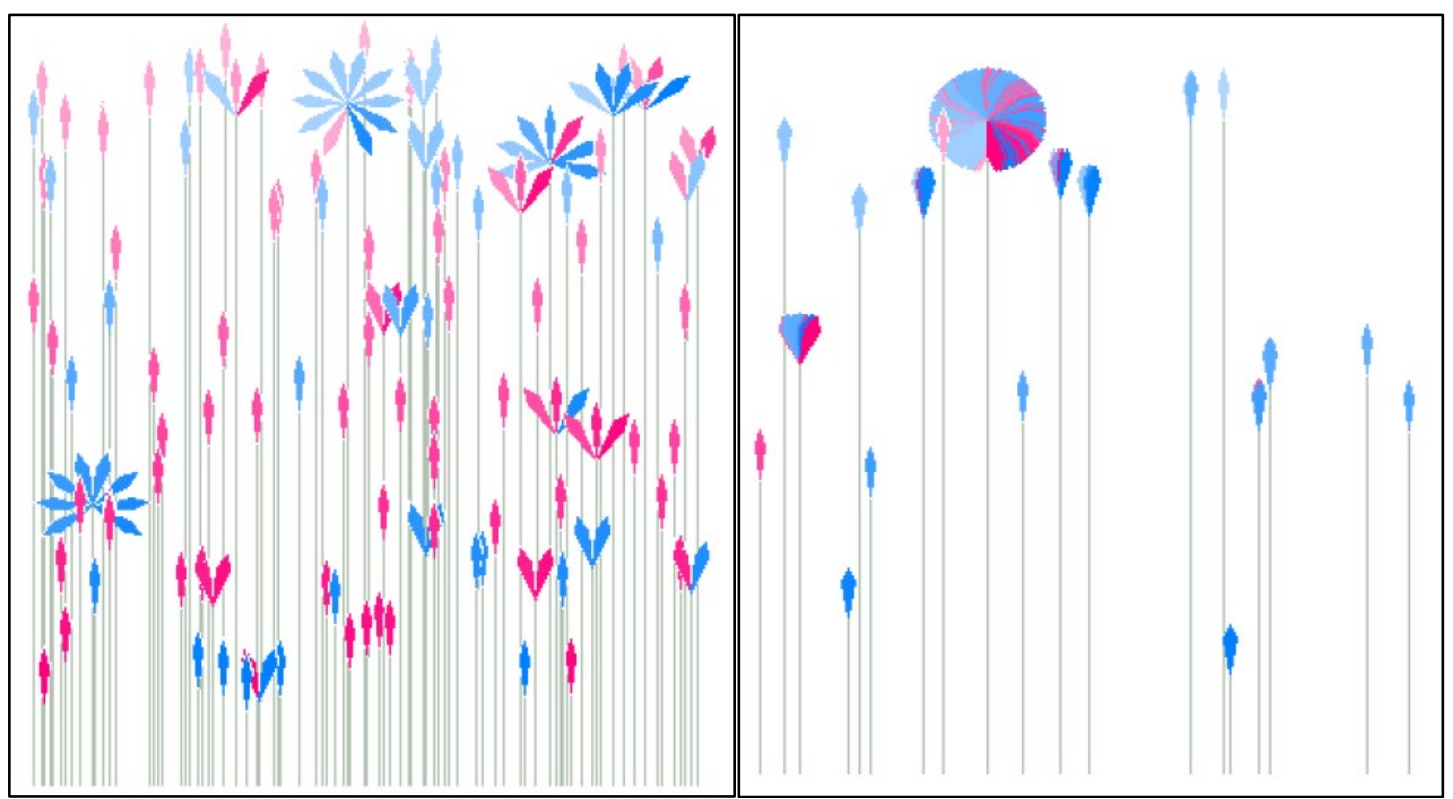

Figure 15. Left side: Example of a democratic discussion; (b) Right side: A discussion with a single dominant participant (Xiong \& Donath, 1999)

\section{Conclusion}

In illustrating the research findings of online discussions, purposes served by visual representations include results from real-time data outputs in naturalistic settings, along with post-hoc representations to facilitate analytical practices. The former includes systems that give teachers a diagnostic dashboard with reference 
to learning activity, including discussion posts, logins, or learning objects accessed (for example TrAVis (May et al., 2011) or GISMO (Mazza \& Botturi, 2007)). The latter has been used to illustrate social structure, critical thinking or sense-making of student-generated text (for example social network analysis through SNAPP (Macfadyen \& Dawson, 2010) or EduMiner (Hsu et al., 2011). The purposes for which these visual representations are being used are diverse, drawing from a range of disciplines and educational settings.

We are asking our diagrams to do a lot - like Tufte's (1990) description of the visualisation of information being an exercise in articulating a world portrayed "in the two-dimensionality of the endless flatlands of paper and screen” (p. 12). As an exercise in mapping experience, diagramming online discussions often depicts quantitative and qualitative data. The interplay of the diagram and words not only illustrates a method, but suggests new ways of looking at the matters of concern in the study. Much of the work of the diagrams described above takes place in the metaphoric mode of correspondence between the represented information and the subject under consideration. The notable exception to this is the contingency graph that traces minute and detailed activity along the process of learning and interaction with technology. Even so, the authors of that study acknowledged that the framework provided by a contingency graph "does not explicitly acknowledge the cultural or historical situatedness of the participants” (Suthers et al.; 2010, p. 28).

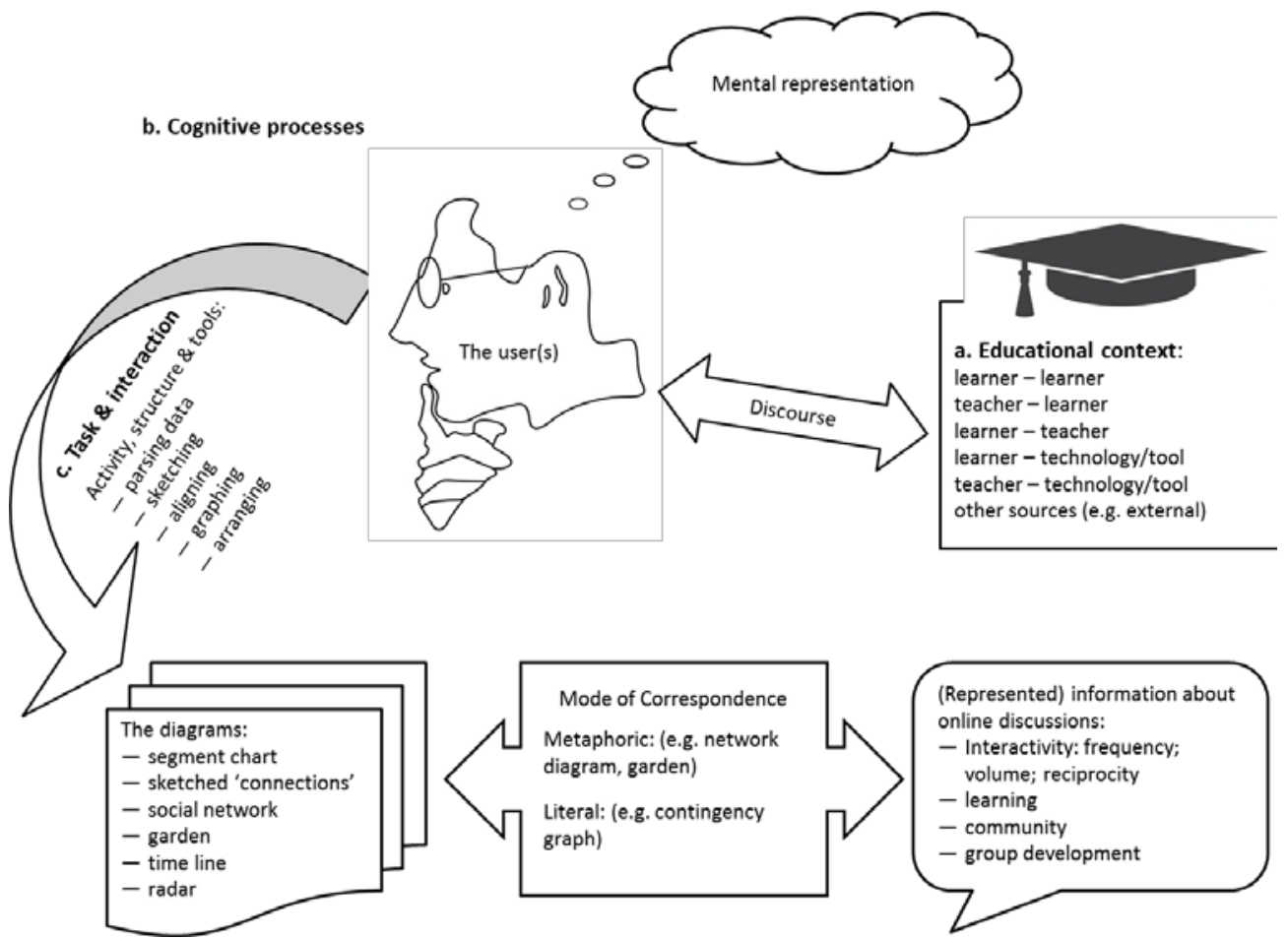

Figure 16. The relationships between the user, the social context and the task being undertaken and interaction with the diagram (adapted from Blackwell \& Engelhart, 2002)

Returning to Blackwell and Engelhart's (2002) taxonomy and in the spirit with which this paper is written, Figure 16 above represents the interaction of their three key contextual elements: (a) a social context (in this case educational); (b) a cognitive process, in this case that of the researcher as user; and (c) the production of the visual itself. Absent is the viewer as interpreter - and participant - in this knowledge practice, traversing as they must between the discursive and the visual. The viewer encounters a representation of the writer's production, arranged for their consumption and consideration. In the absence of its originator, the diagram mediates the meaning of its creator and the viewer, bound in turn by their social context and their visual literacy. While Figure 16 provides a framework for the tracing of diagram conception, context and production, it is in itself the author of this paper's representation of practice - there is little correspondence with those diagrams that precede it above. In seeking to unify the material in this paper, this graphical act makes an attempt to summarise the discussion and could be read in any direction, from the start, end or middle. 
Areas for future consideration in research using diagrams about online discussions might include graphic elicitation - an area conspicuously absent from the studies examined in this review. This might take the form of using SNA or contingency graphs to assist study participants articulate new or novel conceptions of their learning activity, or further extension of learning analytics provided graphically at the classroom (virtual or physical) level. LMS such as Desire2Learn (D2L, 2015) have incorporated this functionality in their systems, but an analysis of the use of this affordance does not have widespread uptake in the literature. Another area for further exploration is to build on the work presented in recent years through the examples shown above. Both the SNA diagram and the contingency graph show significant potential for further use in research practice and there is some evidence of this trend emerging in the use of SNA diagrams. Although diagramming online discussions has appeared in research practices for well over a decade now, it shares limitations noted about diagramming with the wider research community in that it "has developed independently in multiple disciplines under a number of different names, making knowledge transfer regarding this technique difficult” (Umoquit, Tso, Burchett, \& Dobrow, 2011; p. 2). This review is a modest walk-through that may stimulate further consideration of this technique in tracing online conversations as a fast-moving object of analysis.

\section{References}

Barab, S. A., Hay, K. E., \& Yamagata-Lynch, L. C. (2001). Journal of the learning constructing networks of action-relevant episodes: An in situ research methodology. Journal of the Learning Sciences, 10(12), 63-112. http://dx.doi.org/10.1207/S15327809JLS10-1-2_5

Bender, T. (2003). Discussion-based online teaching to enhance student learning: Theory, practice and assessment. Virginia, VA: Stylus Publishing.

Beneito-Montagut, R. (2011). Ethnography goes online: Towards a user-centred methodology to research interpersonal communication on the internet. Qualitative Research, 11(6), 716-735. http://dx.doi.org/10.1177/1468794111413368

Berger, J. (1972). Ways of seeing. London: Penguin Books.

Biggs, J., \& Collis, K. (1982). Evaluating the quality of learning: The SOLO taxonomy. New York, NY: Academic Press.

Blackwell, A., \& Engelhardt, Y. (2002). A meta-taxonomy for diagram research. In M. Anderson, B. Meyer, \& P. Olivier (Eds.), Diagramatic representation and reasoning (pp. 47-64). London: Springer.

Bloom, B. (1956). Taxonomy of educational objectives: The classification of education goals. Cognitive domain. London: Longman.

Bott, H. (1928). Observation of play activities in a nursery school. Genetic Psychology Monographs, 4(1), 44-48.

Chan, J. C. C., Hew, K. F., \& Cheung, W. S. (2009). Asynchronous online discussion thread development: Examining growth patterns and peer-facilitation techniques. Journal of Computer Assisted Learning, 25(5), 438-452. http://dx.doi.org/10.1111/j.1365-2729.2009.00321.x

Crilly, N., Blackwell, A., \& Clarkson, J. (2006). Graphic elicitation: Using research diagrams as interview stimuli. Qualitative Research, 6(3), 341-366. http://dx.doi.org/10.1177/1468794106065007

Cross, R., \& Parker, A. (2004). The hidden power of social networks: Understanding how work really gets done in organisations. Boston, MA: Harvard Business School Press.

D2L (2015). Brightspace for higher education. Retrieved from http://www.brightspace.com/solutions/higher-education/advanced-analytics/

Dawson, S. (2010). "Seeing” the learning community: An exploration of the development of a resource for monitoring online student networking. British Journal of Educational Technology, 41(5), 736752. http://doi.org/10.1111/j.1467-8535.2009.00970.x

Dawson, S., Bakharia, A., Lockyer, L., \& Heathcote, E. (2011). “Seeing” networks: Visualising and evaluating student learning networks Final Report, Strawberry Hills, NSW: Australian Learning and Teaching Council (ALTC).

De Freitas, E. (2012). The classroom as rhizome: New strategies for diagramming knotted interactions. Qualitative Inquiry, 18(7), 557-570. http://dx.doi.org/10.1177/1077800412450155

Dringus, L. P., \& Ellis, T. (2005). Using data mining as a strategy for assessing asynchronous discussion forums. Computers \& Education, 45(1), 141-160. http://dx.doi.org/10.1016/j.compedu.2004.05.003 
Dringus, L. P., \& Ellis, T. (2010). Temporal transitions in participation flow in an asynchronous discussion forum. Computers \& Education, 54(2), 340-349. http://doi.org/10.1016/j.compedu.2009.08.011

Freeman, L. (2004). The development of social network analysis: A study in the sociology of science. Vancouver: Empirical Press.

Garrison, D. R., Anderson, T., \& Archer, W. (1999). Critical inquiry in a text-based environment: Computer conferencing in higher education. The Internet and Higher Education, 2(2-3), 87-105. http://dx.doi.org/10.1016/S1096-7516(00)00016-6

Hara, N., Bonk, C. J., \& Angeli, C. (2000). Content analysis of online discussion in an applied educational psychology course. Instructional Science, 28(2), 115-152. http://dx.doi.org/10.1023/A:1003764722829

Henri, F. (1992). Computer Conferencing and Content Analysis. In A. Kaye (Ed.), Collaborative learning through computer conferencing: The Najaden papers (pp. 117-136). New York, NY: Springer.

Howell-Richardson, C., \& Mellar, H. (1996). A methodology for the analysis of patterns of participation within computer mediated communication courses. Instructional Science, 24(1), 47-69. http://dx.doi.org/10.1007/BF00156003

Hsu, J., Chou, H.-W., \& Chang, H. (2011). EduMiner: Using text mining for automatic formative assessment. Expert Systems with Applications, 38(4), 3431-3439. http://dx.doi.org/10.1016/j.eswa.2010.08.129

Ittelson, W. H. (1996). Visual perception of markings. Psychonomic Bulletin \& Review, 3(2), 171-187. http://dx.doi.org/10.3758/BF03212416

Knowlton, D. (2005). A taxonomy of learning through asynchronous discussion. Journal of Interactive Learning Research, 16(2), 155-177.

LaPointe, D. K., \& Gunawardena, C. N. (2004). Developing, testing and refining of a model to understand the relationship between peer interaction and learning outcomes in computer-mediated conferencing. Distance Education, 25(1), 83-106. http://dx.doi.org/10.1080/0158791042000212477

Latour, B. (1990). Drawing things together. In M. Lynch \& S. Woolgar (Eds.), Representation in Scientific Practice (pp. 19-68). Cambridge: MIT Press.

Liu, C.-C., \& Tsai, C.-C. (2008). An analysis of peer interaction patterns as discoursed by on-line small group problem-solving activity. Computers \& Education, 50(3), 627-639. http://dx.doi.org/10.1016/j.compedu.2006.07.002

Locke, T. (2007). E-learning and the reshaping of rhetorical space. In R. Andrews \& C. Haythornthwaite (Eds.), The Sage handbook of e-learning research. London: Sage Publications.

Locke, T., \& Daly, N. (2006). Politeness and face in digitally reconfigured e-learning spaces. Studies about Languages, 8, 39-50. http://researchcommons.waikato.ac.nz/bitstream/handle/10289/3295/CEEOL_Article1.pdf

Macfadyen, L. P., \& Dawson, S. (2010). Mining LMS data to develop an “early warning system” for educators: A proof of concept. Computers \& Education, 54(2), 588-599. http://dx.doi.org/10.1016/j.compedu.2009.09.008

May, M., George, S., \& Prévôt, P. (2011). TrAVis to enhance students’ self-monitoring in online learning supported by computer-mediated communication tools. International Journal of Information Systems and Industrial Management Applications, 3, 623-634.

Mazza, R., \& Botturi, L. (2007). Monitoring an online course with the GISMO tool: A case study. Journal of Interactive Learning Research, 18(2), 251-265.

Moreno, J. (1953). Who shall survive? (2nd ed.). New York, NY: Beacon House.

Oliveira, I., Tinoca, L., \& Pereira, A. (2011). Online group work patterns: How to promote a successful collaboration. Computers \& Education, 57(1), 1348-1357. http://dx.doi.org/10.1016/j.compedu.2011.01.017

Olivera, F., Goodman, P., \& Tan, S. (2008). Contribution behaviors in distributed environments. MIS Quarterly, 32(1), 23-42. http://www.jstor.org/stable/25148827

Richardson, J. C., \& Ice, P. (2010). Investigating students' level of critical thinking across instructional strategies in online discussions. The Internet and Higher Education, 13(1-2), 52-59. http://dx.doi.org/10.1016/j.iheduc.2009.10.009

Rogers, E. (2003). Diffusion Networks. In R. Cross, A. Parker, \& L. Sasson (Eds.), Networks in the knowledge economy. New York, NY: Oxford University Press.

Schrire, S. (2004). Interaction and cognition in asynchronous computer conferencing. Instructional Science, 32(6), 475-502. http://dx.doi.org/10.1007/s11251-004-2518-7 
Schrire, S. (2006). Knowledge building in asynchronous discussion groups: Going beyond quantitative analysis. Computers \& Education, 46(1), 49-70. http://dx.doi.org/10.1016/j.compedu.2005.04.006

Stevens, T. (2013). Who you know and what you know: Student interaction in online discussions. Australian Educational Computing, 28(1), 47-60.

Suthers, D., Dwyer, N., Medina, R., \& Vatrapu, R. (2010). A dramework for conceptualizing, representing, and analyzing distributed interaction. International Journal of Computer Supported Collaborative Learning, 5(1), 5-42. http://dx.doi.org/10.1007/s11412-009-9081-9

Svensson, P. (2009). From re-presentation to re-creation: Contributing to a radicalisation of linguistically turned interviewing in management studies. Qualitative Research in Organizations and Management: An International Journal, 4(2), 168-185. http://dx.doi.org/10.1108/17465640910978418

Tufte, E. (1990). Envisioning Information, Connecticut, CT: Graphics Press LLC

Umoquit, M. J., Tso, P., Burchett, H. E. D., \& Dobrow, M. J. (2011). A multidisciplinary systematic review of the use of diagrams as a means of collecting data from research subjects: Application, benefits and recommendations. BMC Medical Research Methodology, 11(1), 11. http://dx.doi.org/10.1186/1471-2288-11-11

Wellman, B. (1926). The school child's choice of companions. Journal of Educational Research, 14(2), 126-132. http://dx.doi.org/10.1080/00220671.1926.10879675

Whetten, D. A. (1989). What constitutes theoretical contribution? The Academy of Management Journal, 14(4), 490-495. http://dx.doi.org/10.5465/AMR.1989.4308371

Xiong, R., \& Donath, J. (1999). PeopleGarden: Creating data portraits for users. Proceedings of ACM symposium on user interface software and technology, New York, NY, pp. 37-44. http://dx.doi.org/10.1145/320719.322581

Corresponding author: Tony Stevens, email t.stevens5@student.unimelb.edu.au

Australasian Journal of Educational Technology (C) 2016.

Please cite as: Stevens, T. (2016). I "see” what you are saying: The analytical work of diagrams in online discussions. Australasian Journal of Educational Technology, 32(4), 50-67. 
Appendix A

Table of journal articles

\begin{tabular}{|c|c|c|}
\hline Author(s) & Journal & Matter of concern \\
\hline Dawson (2010) & $\begin{array}{l}\text { British Journal of Educational } \\
\text { Technology }\end{array}$ & $\begin{array}{l}\text { Observing a learning community } \\
\text { develop }\end{array}$ \\
\hline $\begin{array}{l}\text { Hara, Bonk, \& Angeli } \\
\text { (2000) }\end{array}$ & Instructional Science & $\begin{array}{l}\text { Participation, interaction and message } \\
\text { content }\end{array}$ \\
\hline $\begin{array}{l}\text { Hsu, Chou, \& Chang } \\
\text { (2011) }\end{array}$ & Expert Systems with Applications & $\begin{array}{l}\text { Interpreting content and providing } \\
\text { feedback to students }\end{array}$ \\
\hline Liu \& Tsai (2008) & Computers \& Education & Peer interaction in problem solving \\
\hline $\begin{array}{l}\text { Macfadyen \& Dawson } \\
(2010)\end{array}$ & Computers \& Education & $\begin{array}{l}\text { Identifying students at risk through } \\
\text { social network analysis }\end{array}$ \\
\hline $\begin{array}{l}\text { May, George, \& Prevot } \\
\text { (2011) }\end{array}$ & $\begin{array}{l}\text { International Journal of Computer } \\
\text { Information Systems and Industrial } \\
\text { management Applications }\end{array}$ & $\begin{array}{l}\text { Feedback to assist in self-monitoring for } \\
\text { students }\end{array}$ \\
\hline $\begin{array}{l}\text { Oliveira, Tinoca, \& } \\
\text { Pereira (2011) }\end{array}$ & Computers \& Education & Collaboration in online discussions \\
\hline Shrire (2004; 2006) & Computers \& Education & $\begin{array}{l}\text { Micro-level analysis of discussion } \\
\text { dynamics }\end{array}$ \\
\hline Stevens (2013) & Australian Educational Computing & $\begin{array}{l}\text { Choice of correspondent(s) in } \\
\text { discussion responses }\end{array}$ \\
\hline $\begin{array}{l}\text { Suthers, Dwyer, Medina, } \\
\text { \& Vatrapu (2010) }\end{array}$ & $\begin{array}{l}\text { International Journal of Computer } \\
\text { Supported Collaborative Learning }\end{array}$ & $\begin{array}{l}\text { Sequential and situational context: } \\
\text { process and content }\end{array}$ \\
\hline Xiong \& Donath (1999) & MIT Media Laboratory & Conversation development \\
\hline
\end{tabular}

